\title{
Sherds as archaeobotanical assemblages: Gua Sireh reconsidered
}

[final manuscript, published in Antiquity 94 (370): 1325-1336

https://doi.org/10.15184/aqy.2020.166]

Aleese Barron ${ }^{1, *}$, Ipoi Datan ${ }^{2}$, Peter Bellwood ${ }^{1}$, Rachel Wood ${ }^{1,3}$, Dorian Q Fuller ${ }^{4,5}$ \& Tim Denham $^{1}$

${ }^{1}$ School of Archaeology and Anthropology, Australian National University, Canberra, Australia

${ }^{2}$ Retired Director of Sarawak Museum, Kuching, Malaysia

${ }^{3}$ Research School of Earth Sciences, Australian National University, Canberra, Australia

${ }^{4}$ Institute of Archaeology, University College London, UK

${ }^{5}$ Northwest University, School of Cultural Heritage, Shanxi, China

*Author for correspondence $\square$ :Aleese.Barron@anu.edu.au

The earliest date for domesticated rice in Island Southeast Asia (4960-3565 cal BP) comes from a single grain embedded in a ceramic sherd from Gua Sireh cave, Borneo. In a first assessment of spikelet base assemblages within pottery sherds using quantitative microCT analysis, we found no additional rice remains within this sherd to support the early date of rice farming; analysis of a more recent Gua Sireh sherd (1990-830 cal BP), however, indicates that 78 per cent of spikelet bases are from domesticated rice. The results demonstrate that the technique offers a high degree of contextual and temporal resolution for approaching organic-tempered ceramics as well-preserved archaeobotanical assemblages.

Keywords: Island Southeast Asia, Borneo, archaeobotany, rice domestication, microCT

\section{Introduction}

The archaeobotanical record of early (pre-3000 cal BP) domesticated rice (Oryza sativa) in Island Southeast Asia largely relies on the presence in pottery sherds of husk impressions and inclusions, and, occasionally, adhering grains (Snow et al. 1986; Bellwood et al. 1992; Paz 1999, 2005; Doherty et al. 2000; Castillo \& Fuller 2010; Barker et al. 2011). Problematically, these types of 'rice-associated pottery' have been presented as the earliest evidence for the 
introduction of rice farming into the region (Snow et al. 1986; Bellwood et al. 1992; Beavitt et al. 1996), despite the uncertain domestication status of the associated rice. Finds have often been assumed to represent domesticated rice based on grain or husk morphology, which is not diagnostic of domestication within Oryza species. Assessment of the abscission scar on spikelet bases is considered the most reliable diagnostic marker of domesticated rice in macrobotanical assemblages (Thompson 1992; Fuller et al. 2009). Without assessment of this marker, early rice-associated pottery could indicate either intentional or incidental inclusion of native wild rice.

The oldest rice-associated pottery in Island Southeast Asia was recovered in 1989 during excavations at the cave of Gua Sireh in south-western Sarawak on Borneo (Ipoi \& Bellwood 1991; Ipoi 1993). A single, charred rice grain was found embedded in the surface of a sherd and subsequently radiocarbon-dated to 4960-3565 cal BP (Figure 1; Table S1; $3850 \pm 260$ uncal BP, CAMS-725; Bellwood et al. 1992). Rice husks were also reported from comparable stratigraphic contexts at Gua Sireh (Beavitt et al. 1996). Despite the imprecision of the radiocarbon date, the Gua Sireh find is anomalously old compared with other reliable finds of rice-associated pottery from Island Southeast Asia (Paz 2005), and up to 1000 years older than the estimated timeline for Neolithic expansion into the region (Bellwood 2017: 273-74). The curious case of this single pottery sherd outlier invited re-analysis to clarify the chronology of early rice cultivation in Island Southeast Asia.

Here we present the results of penetrative but non-destructive microCT analysis of two sherds from Gua Sireh: the anomalously old sherd (CAMS-725) and a more recent sherd directly dated to 1990-830 cal BP (Table S1; 1480 260 uncal BP, CAMS-721; Bellwood et al. 1992). The objective is to determine the presence and domestication status of associated rice through analysis of spikelet bases included within the organic temper of the ceramic sherds. Previous qualitative development of microCT technology applied to the investigation of domesticated rice within pottery sherds (Barron et al. 2017; Barron \& Denham 2018) is extended here through the quantitative assessment of spikelet base assemblages. Our results demonstrate that organic inclusions within each sherd function as a discrete, well-preserved archaeobotanical assemblage.

\section{The early (pre-3000 cal BP) dispersal of rice in Island Southeast Asia}

Current archaeobotanical evidence suggests that rice was first domesticated in the middle and lower reaches of the Yangtze Valley c. 8000-6000 cal BP, following a protracted period of 
pre-domestication cultivation (Fuller et al. 2009; Deng et al. 2015). Subsequently, rice cultivation spread to southern China by $c$. 5000-4700 cal BP, to southern Vietnam by $c$. 4150-3265 cal BP and to Taiwan by at least $4200 \mathrm{cal}$ BP and possibly as early as $4800 \mathrm{cal}$ BP (Bellwood et al. 2011; Barron et al. 2017; Castillo et al. 2017; Deng et al. 2018; Yang et al. 2018). Rice-associated pottery from Andarayan in northern Luzon (Philippines) was directly dated to $3970-3380$ cal BP (Table S1; 3400 \pm 125 uncal BP; lab code not provided; Snow et al. 1986: 5), and was inferred to have been made locally; it is currently the oldest putative evidence for cultivated rice in the Philippines.

The early Gua Sireh sherd, dated to 4960-3565 cal BP (CAMS-725), is anachronistic when compared to the chronological framework for both the domestication of rice in East Asia and the dispersal of rice cultivation through Southeast Asia. Although comparably aged rice-tempered pottery on Borneo is claimed in association with a burial dated to almost 5000 cal BP at Niah Cave (Doherty et al. 2000), this find is neither confirmed nor discussed in later publications (Barker \& Richards 2013; Barker \& Farr 2016). Furthermore, Doherty et al. (2000: 148) identified rice in sherds from 35 sites across Borneo "covering the period from 4000-3000 BP to 400 BP", but neither the imaging nor dating of these sherds have been fully published to enable independent assessment. Doherty et al. (2000) suggested that rice in pottery from early sites (i.e. predating $3000 \mathrm{cal} \mathrm{BP}$ ) was relatively sparse and suggestive of incidental inclusion during the manufacturing process, rather than intentional addition as temper. They propose that rice remains only became a popular tempering material on Borneo after $1000 \mathrm{cal}$ BP. The current evidence does not point to significant open field rice cultivation in most regions of Island Southeast Asia before 2000 cal BP (discussed in Donohue \& Denham 2010).

Regardless of the imprecise age estimates for this early inclusion of rice, a significant methodological issue prevents the establishment of an irrefutable link between riceassociated pottery and the introduction of cereal agriculture to Borneo (cf. Hayden 2011; Barton 2012). The occurrence of rice does not necessarily mean the presence or cultivation of domesticated rice (Oryza sativa), as a number of wild rice species grow across the island (contra Beavitt et al. 1996: 30). Conceivably, these could have been exploited long before the introduction of domesticated rice cultivation by people engaged in foraging. Modern wild rice distributions (Vaughan 1994; Fuller et al. 2010), as well as early Holocene palaeoenvironmental records, such as the Loagan Bunut lake core on Borneo (Hunt \& Premathilake 2012), show the spatial and temporal prevalence of wild rice species. Rice 
appearing in the archaeological record, particularly in small quantities, may therefore be potentially associated with wild rice foraging practices and need not imply cultivation.

\section{Methods}

Thompson (1992) first developed the method to discriminate domesticated rice in macrobotanical assemblages using the distinctive abscission scar, namely the detachment mark, on spikelet bases. This scar represents anthropic selection for non-shattering seed dispersal, as opposed to the natural shattering dispersal mechanism of wild species. This method was refined and applied by Fuller et al. (2009) to archaeobotanical assemblages at multiple sites in the Yangtze Basin (Fuller \& Qin 2008; Fuller et al. 2014; see 'spikelet reference images' in the online supplementary material (OSM)). At maturation, abscission in wild rice leaves a smooth, concave and round depression after the spikelet detaches. In contrast, domesticated scars are torn out, leaving a deep and irregular pit in place of the abscission layer; in addition, these pits tend to be asymmetric rather than round. Greenharvested (or "immature") types are identified by a protruding scar, in which some of the rachilla vasculature is still attached to the spikelet base indicating that it has been broken off before it is ripe (Fuller et al. 2009). In cases where the above criteria are obscured, spikelet bases are classified as indeterminate.

The discrimination of spikelet base morphology has not previously been used to verify claims for domesticated rice associated with pottery in Island Southeast Asia. Thompson (1992) had limited success in the application of this technique to the investigation of rice-tempered pottery sherds; spikelet bases were often too damaged or fragile for further analysis following manual extraction of the samples from the pottery. Barron et al. (2017) have recently demonstrated the utility of microCT imaging for the high-resolution, penetrative 3D visualisation of rice spikelet bases within pottery sherds from Vietnam. Images of organic materials within the sherd were of sufficient resolution to determine qualitatively the domestication status of rice spikelet bases. The technique has so far not been applied to the quantitative investigation of rice-associated pottery.

The Gua Sireh sherds were scanned at the National Laboratory for X-ray Micro Computed Tomography (CTLab) at the Australian National University. The sherds were placed in an aluminium tube, secured with packing foam, and required no further sample preparation. They were scanned using high-resolution helical-CT (ANU4) with a $2 \mathrm{~mm}$ aluminium filter at $100 \mathrm{kV}$ and $50 \mu \mathrm{A}$, resulting in a $16.7 \mu \mathrm{m}$ voxel size (Latham et al. 2008; 
Myers et al. 2011). The datasets were then visually rendered using Drishti Paint v2.4.6 and Drishti Renderer v2.4.6 (Limaye 2012).

Initially, the dataset for each sherd was viewed in low resolution, specifically at $1 / 64^{\text {th }}$ of maximal resolution, to identify organic inclusions within the pottery matrix. Organic inclusions are readily identifiable due to lower X-ray attenuation, representing lower densities relative to the clay matrix and mineral temper. We determined the spatial limits of inclusions of interest before subjecting them to high-resolution (namely, with $16.7 \mu \mathrm{m}$ resolution) three dimensional visualisation and targeted morphological analysis to identify rice spikelet bases (Barron \& Denham 2018). Where possible, quantitative analysis was designed to evaluate a minimum of 100 rice spikelet bases within a sherd and to create accompanying visualisations of 50 spikelet bases within each sherd. Rice spikelet bases were classified into wild, domesticated, immature and indeterminate types using reference images (Fuller et al. 2009; Deng et al. 2015; see 'spikelet reference images' in the OSM).

\section{Results}

MicroCT analysis of the two dated sherds from Gua Sireh under study indicate sparse organic remains within the older sherd (CAMS-725) and abundant organic remains distributed throughout the more recent sherd (CAMS-721) (Figure 2). Visual inspection suggests that organic inclusions had been converted to charcoal, as a result of being encased within a lowoxygen environment during firing of the pottery. Although the organic materials are highly fragile and prone to disintegration upon disturbance, they are well-preserved in situ. Attempts to date rice spikelet bases encased within the more recent sherd were, however, unsuccessful, possibly due to mineral replacement of the organic inclusions (see 'attempted radiocarbon dating' in the OSM). Nonetheless, the hard pottery fabric preserved high levels of morphological detail of the encased organic remains. There were several regions of interest within the older sherd, namely areas that displayed X-ray attenuation values of the expected range for organic materials (Figure 2B). Although these were subsequently investigated in high resolution, none exhibited distinctive rice husk or spikelet base morphologies when imaged individually. Thus, given the absence of rice remains or other suitable organic materials within the sherd, it was not possible to obtain another AMS date for this sherd.

We were able to assess the probable affiliation of the AMS-dated rice grain (CAMS725) embedded on this sherd (Figure 1). Grain dimensions, as measured from the photograph, estimate a length/width $(\mathrm{L} / \mathrm{W})$ ratio of 2.86. Given the oblique angle of the grain, this could be an over-estimate. A ratio of 2.5 would probably be an underestimate based on likely length 
and width measurements of the grain; the true $\mathrm{L} / \mathrm{W}$ ratio is likely to fall somewhere between 2.5 and 2.86. This is significant because $\mathrm{L} / \mathrm{W}$ ratios in rice of subspecies japonicaare usually less than 2.2 and not more than 2.5. Ratios greater than 2.5 are present in the subspecies indica and are typical of wild rice species (Castillo et al. 2016: fig. 8). Early examples of archaeological rice in mainland Southeast Asia appear to be entirely of the subspecies japonica derived from domestication in China; the indica subspecies is unlikely to have been introduced before 2000 cal BP (Castillo 2011; Castillo et al. 2016, 2018). Thus, considering the antiquity of the Gua Sireh context on Borneo, the morphology of this grain is consistent with a species of wild rice.

The more recent sherd (CAMS-721) contains abundant organic remains, including rice spikelet bases and husks (Figure 2). Fifty spikelet bases were individually rendered and visualised, with the intention of determining the domestication status of Oryza sativa inclusions (see 'rice spikelet base visualisations' in the OSM). The high levels of morphological detail preserved and the high scanning resolution enable virtual inspection of the abscission scar on each spikelet base. Of these, 78 per cent were determined to be of a domesticated type $(n=39$; Figure $3 A-C)$, two per cent were indeterminate $(n=1$; Figure $3 D)$, 16 per cent were of a distinct wild type $(n=8$; Figure $3 E-F)$ and four per cent were derived from a different wild rice species (Oryza sp.; n=2; Figure 4) (Table S2). The immature form was not present.

\section{Discussion}

The re-analysis of the two Gua Sireh sherds demonstrates the value of microCT for investigating rice-associated pottery in Island Southeast Asia. The archaeobotanical evidence associated with putatively early sherds in the region comprises surface impressions and inclusions of rice husks within the pottery fabric. MicroCT is an efficient technique that makes it possible to visualise in 3D rice spikelet bases and other organic remains, where present, throughout the thickness of an entire sherd. The technique is not limited to surface analysis and does not require any breakage to retrieve archaeobotanical samples. MicroCT thus has the potential to revolutionise the investigation of plant domestication and dispersal in the past, by transforming individual pottery sherds into well-preserved archaeobotanical assemblages.

MicroCT analysis of the older sherd (CAMS-725) confirms that it was not ricetempered. Aside from the single charred grain from the surface, no other inclusions or impressions of rice grains, husks or spikelet bases were found within the sherd, nor were they 
present on its exterior surfaces. The absence of any other rice remains within this sherd leaves two possible explanations for the presence of the single grain: either prior incorporation within the raw clay deposit or incidental inclusion during the manufacturing process. The embedded grain was originally identified as 'carbonised rice' due to the distinctive 'checkerboard' patterning on the husk (Bellwood et al. 1992). The absence of the spikelet base hinders determination of domestication status, while the estimated length:width ratio best corresponds with a wild type of rice. It should also be noted that, even if the grain's spikelet base morphology could be assessed, little could be deduced about the domestication status of larger rice populations from a single specimen. The spikelet base methodology for identifying domesticated rice relies on proportional counts of morphological types, and therefore requires both quantitative and qualitative evaluation. Conservatively, the grain attests to the presence of wild rice growing on Borneo c. 4960-3565 cal BP but does not provide evidence for the introduction of rice cultivation from mainland Southeast Asia at this time.

Sherd CAMS-721 contained abundant rice spikelet bases, of which 50 were imaged. The spikelet base assemblage is consistent with that associated with the cultivation of domesticated rice (Fuller et al. 2009, 2014, 2016) in that it is dominated by domesticated types (78 per cent). In total, wild rice types represented 20 per cent of the assemblage, which suggests that weedy forms were harvested together with domesticated rice. These proportions of domesticated and wild types are consistent with assemblages ranging from 5000-4000year-old agricultural sites in China (20-25 per cent; Fuller et al. 2009) to Iron Age (c. 25001400 cal BP) sites in Thailand (2-12\%; Castillo et al. 2016: tab. 6). Thus, the assemblage within the more recent Gua Sireh sherd is consistent with its age of c. 2000-800 cal BP, namely the period during which open field rice cultivation became widespread across Island Southeast Asia (Donohue \& Denham 2010).

Significantly, the presence of two spikelet bases ( 4 per cent) derived from an unidentified wild rice species indicates the incidental exploitation of wild rice species potentially growing in plots alongside domesticated rice. In domesticated rice and its wild progenitors (Oryza rufipogon, sensu lato), the spikelet base attaches to the rachilla on one side. This seems to characterise the AA-genome groups within the genus Oryza (Vaughan 1994), which include domesticated Asian rice and domesticated African rice, as well as wild relatives. In other Oryza species, however, the rachilla attaches from below, leading to a squatter spikelet base and an abscission scar at the attenuating base of the spikelet rather than on one side. This is typical of non-AA genome wild Oryza spp., comparable to Oryza 
officinalis (Fuller et al. 2011: plate 12.3). This trait is probably ancestral, as it is shared with related genera such as Zizania, Leersia and Hydrochloa (Weatherwax 1929), whereas the side attachment characterises wild and domesticated AA Oryza species. The two non-AA type spikelet bases in sherd CAMS-721 suggest the presence of indigenous wild rice species on Borneo (O. officinalis, O. meyeriana, or O. ridleyi; Vaughan 1994), which sometimes grow as weeds within domesticated rice plots, and can be harvested and processed along with domesticated rice. All are shade tolerant species and can be expected to grow in plots adjacent to forest (Weisskopf et al. 2014).

\section{Conclusion}

MicroCT analysis of pottery sherds is non-destructive and enables high-resolution visualisation of delicate organic remains preserved within hard, protective ceramic fabrics. The technique has great potential for the investigation of plant remains encased within sherds at sites where macrobotanical preservation may otherwise be poor, such as the wet tropics and some semi-arid and arid environments.

The re-analysis of sherds from Gua Sireh has clarified an anomaly of the Southeast Asian archaeological record, namely purported evidence of domestic rice on Borneo by 4960-3565 cal BP. The rice grain embedded in the sherd's surface (CAMS-725) probably represents the incidental inclusion of a native wild rice species growing locally on Borneo. The absence of suitable dating material precludes re-analysis of the age of this sherd.

The analysis of the more recent sherd (CAMS-721) demonstrates the suitability of microCT to image a large number of rice spikelet bases non-destructively, so that proportional quantitative counts of abscission scar morphologies can be compiled for a single sherd. High-resolution data was obtained for 50 spikelet bases within the sherd. Overall, this

study demonstrates the potential of microCT to transform individual pottery sherds into wellpreserved, as well as stratigraphically and temporally well-constrained, archaeobotanical assemblages.

\section{Acknowledgements}

The authors would like to thank the National Laboratory for X-ray Micro Computed Tomography at the Australian National University (ANU CTLab), particularly Levi Beeching and Michael Turner, for access to and use of CT scanning facilities, and Tim Senden, Research School of Physics and Engineering (ANU) for his continued guidance and support. Spikelet bases of multiple rice species were examined in the UCL archaeobotany reference 
collection. Thanks are also due to Richard Gillespie for sharing his images and recollections of previous dating protocols, and to Rebecca Esmay for her careful work pre-treating such a tiny sample for radiocarbon dating. This research is supported by the Australian Government Research Training Program (RTP) Scholarship and the Australian Research Council Future Fellowship (FT150100420). Many thanks to the two anonymous reviewers for greatly improving the manuscript.

\section{References}

BARKER, G. \& M.B. RICHARDS. 2013. Foraging-farming transitions in Island Southeast Asia. Journal of Archaeological Method and Theory 20: 256-80. https://doi.org/10.1007/s10816012-9150-7

BARKER, G. \& L. FARr. 2016. Archaeological investigations in the Niah Caves, Sarawak. Cambridge: McDonald Institute of Archaeological Research.

BARKer, G., C. HunT \& J. CARLos. 2011. Transitions to farming in Island Southeast Asia: archaeological, biomolecular and palaeoecological perspectives, in G. Barker \& M. Janowski (ed.) Why cultivate? Anthropological and archaeological approaches to foraging-farming transitions in Southeast Asia: 61-74. Oxford: McDonald Institute for Archaeological Research

BARRon, A. \& T. DENhAM. 2018. A microCT protocol for the visualisation and identification of domesticated plant remains within pottery sherds. Journal of Archaeological Science Reports 21: 350-58. https://doi.org/10.1016/j.jasrep.2018.07.024

BARRON, A. et al. 2017. MicroCT reveals domesticated rice (Oryza sativa) within pottery sherds from early Neolithic sites (4150-3265 cal BP) in Southeast Asia. Scientific Reports 7: 7410. https://doi.org/10.1038/s41598-017-04338-9

BARTON, H. 2012. The reversed fortunes of sago and rice, Oryza sativa, in the rainforests of Sarawak, Borneo. Quaternary International 249: 96-104.

https://doi.org/10.1016/j.quaint.2011.03.037

BeavitT, P., E. Kurui \& G.B. ThOMPSON. 1996. Confirmation of an early date for the presence of rice in Borneo: preliminary evidence for possible Bidayuh/Asian links. Borneo Research Bulletin 27: 29-33.

BELLWOOD, P. 2017. First islanders: prehistory and human migration in Island Southeast Asia. Oxford: Wiley Blackwell. https://doi.org/10.1002/9781119251583 
Bellwood, P., R. Gillespie, G.B. Thompson, J.S. Vogel, I.W. Ardika \& I. Datan. 1992. New dates for prehistoric Asian rice. Asian Perspectives 31: 161-70.

Bellwood, P. et al. 2011. An Son and the Neolithic of Southern Vietnam. Asian

Perspectives 50: 144-75. https://doi.org/10.1353/asi.2011.0007

CASTILlo, C. 2011. Rice in Thailand: the archaeobotanical contribution. Rice 4: 114-20.

https://doi.org/10.1007/s12284-011-9070-2

Castillo, C. \& D.Q. Fuller. 2010. Still too fragmentary and dependent upon chance?

Advances in the study of early Southeast Asian archaeobotany, in B. Bellina (ed.) 50 years of archaeology in Southeast Asia: essays in honour of Ian Glover: 91-111. London: River Books.

CASTILLO, C. et al. 2016. Archaeogenetic study of prehistoric rice remains from Thailand and India: evidence of early japonica in South and Southeast Asia. Archaeological and Anthropological Sciences 8: 523-43. https://doi.org/10.1007/s12520-015-0236-5

Castillo, C., D.Q. Fuller, P.J. PiPer, P. BellwoOd \& M. OXenhaM. 2017. Hunter-gatherer specialization in the late Neolithic of southern Vietnam: the case of Rach Nui. Quaternary International 489: 63-79. https://doi.org/10.1016/j.quaint.2016.11.034

Castillo, C., C. Higham, K. Miller, N. Chang, K. Douka, T. Higham \& D. Q. Fuller. 2018. Social responses to Climate change in Iron Age Northeast Thailand: new archaeobotanical evidence. Antiquity 92: 1274-91. https://doi.org/10.15184/aqy.2018.198 Deng, Z., L. Qin, Y. GAO, A. Weisskopf, C. Zhang \& D.Q. Fuller. 2015. From early domesticated rice of the Middle Yangtze Basin to millet, rice and wheat agriculture: archaeobotanical macro-remains from Baligang, Nanyang Basin, Central China (6700-500 BC). PLoS One 10: e0139885. https://doi.org/10.1371/journal.pone.0139885

Deng, Z., H.C. Hung, X. FAN, Y. HuANG \& H. LU. 2018. The ancient dispersal of millets in southern China: new archaeological evidence. The Holocene 28: 34-43.

https://doi.org/10.1177/0959683617714603

DOHERTY, C., P. BEAVITT \& E. KURUI. 2000. Recent observations of rice temper in pottery from Miah and other sites in Sarawak. Indo-Pacific Prehistory Association Bulletin 20(4): 147-152. https://doi.org/10.7152/bippa.v20i0.11750

Donohue, M. \& T. Denham. 2010. Farming and language in Island Southeast Asia: reframing Austronesian history. Current Anthropology 51: 223-56. https://doi.org/10.1086/650991 FULLER, D.Q. \& L. QIN. 2008. Immature rice and its archaeobotanical recognition: a reply to Pan. Antiquity 82: 316. https://doi.org/10.1017/S0003598X0009520X 
Fuller, D.Q., L. Qin, Y. Zheng, Z. ZhaO, X. Chen, L.A. Hosoya \& G.-P. Sun. 2009. The domestication process and domestication rate in rice: spikelet bases from the Lower Yangtze. Science 323: 1607-10. https://doi.org/10.1126/science.1166605

Fuller, D.Q., Y.-I. Sato, C. CAstillo, L. Qin, A.R. Weisskopf, E.J. Kingwell-BanhaM, J. Song, S.-M. Ahn \& J. VAn EtTEn. 2010. Consilience of genetics and archaeobotany in the entangled history of rice. Archaeological and Anthropological Sciences 2: 115-31. https://doi.org/10.1007/s12520-010-0035-y

Fuller, D.Q., T. Denham, M. Arroyo-Kalin, L. LuCas, C.J. Stevens, L. Qin, R. Allaby \& M.D. Purugganan. 2014. Convergent evolution and parallelism in plant domestication revealed by an expanding archaeological record. Proceedings of the National Academy of Sciences of the USA 111: 6147-52. https://doi.org/10.1073/pnas.1308937110 Fuller, D.Q., A.WEISSKOPF \& C. CASTILlo 2016. Pathways of rice diversification across Asia. Archaeology International 19: 84-96. https://doi.org/10.5334/ai.1915 HAYDEN, B. 2011. Rice: the first Asian luxury food?, in G. Barker and M. Janowski (ed.) Why cultivate? Anthropological and archaeological approaches to foraging-farmer transitions in Southeast Asia: 75-93. Cambridge: McDonald Institute Monographs. Hunt, C.O. \& R. PremathilaKe. 2012. Early Holocene vegetation, human activity and climate from Sarawak, Malaysian Borneo. Quaternary International 249: 105-19. https://doi.org/10.1016/j.quaint.2011.04.027

IPOI, D. 1993. Archaeological excavations at Gua Sireh (Serian) and Lubang Angin (Gunung Mulu National Park), Sarawak, Malaysia. Sarawak Museum Journal 45: Special Monograph 6.

IPOI, D. \& P. BELLWOOD. 1991. Recent research at Gua Sireh (Serian) and Lubang Angin (Gunung Mulu National Park), Sarawak. Bulletin of the Indo-Pacific Prehistory Association 11: $386-405$.

LATHAM, S., T. VARSLOT \& A. ShEPPARD 2008. Automated registration for augmenting micro-CT 3D images. Australian and New Zealand Industrial and Applied Mathematics Journal 50: C534-48. https://doi.org/10.21914/anziamj.v50i0.1389

LiMAYE, A. 2012 Drishti: a volume exploration and presentation tool. SPIE Proceedings, Developments in X-Ray Tomography 8: 8506. https://doi.org/10.1117/12.935640 Myers, G., A. Kingston, T. VARSLOT \& A. ShePPARD 2011. Extending reference scan drift correction to high-magnification high-cone-angle tomography. Optics Letters 36: 4809-11. https://doi.org/10.1364/OL.36.004809 
PAZ, V. 1999. Neolithic human movement to Island Southeast Asia: the search for archaeobotanical evidence. Bulletin of the Indo-Pacific Prehistory Association 18: 151-57. https://doi.org/10.7152/bippa.v18i0.11710

- 2005. Rock shelters, caves, and archaeobotany in Island Southeast Asia. Asian Perspectives 44: 107-18. https://doi.org/10.1353/asi.2005.0012

Snow, B.E., R. Shutler, D.E. Nelson, J.S. Vogel \& J.R. Southon. 1986. Evidence of early rice cultivation in the Philippines. Philippine Quarterly of Culture and Society 14: 3-11. Thompson, G.B. 1992. Archaeobotanical investigations at Khok Phanom Di, Central Thailand. Unpublished PhD Dissertation, Australian National University.

VAUGHAN, D.A. 1994. The Wild relatives of rice: a genetic resources handbook. Los Baños: International Rice Research Institute.

Weatherwax, P. 1929. The morphology of the spikelets of six genera of Oryzeae. American Journal of Botany 16: 547-55. https://doi.org/10.1002/j.1537-2197.1929.tb09502.x Weisskopf, A., E. Harvey, E. Kingwell-Banham, M. Kajale, R. Mohanty \& D.Q. FULLER. 2014. Archaeobotanical implications of phytolith assemblages from cultivated rice systems, wild rice stands and macro-regional patterns. Journal of Archaeological Science 51: 43-53. https://doi.org/10.1016/j.jas.2013.04.026

YANG, X. et al. 2018. New radiocarbon and archaeobotanical evidence reveal the timing and route of southward dispersal of rice farming in south China. Science Bulletin 63: 1495-1501. https://doi.org/10.1016/j.scib.2018.10.011

\section{Figures}




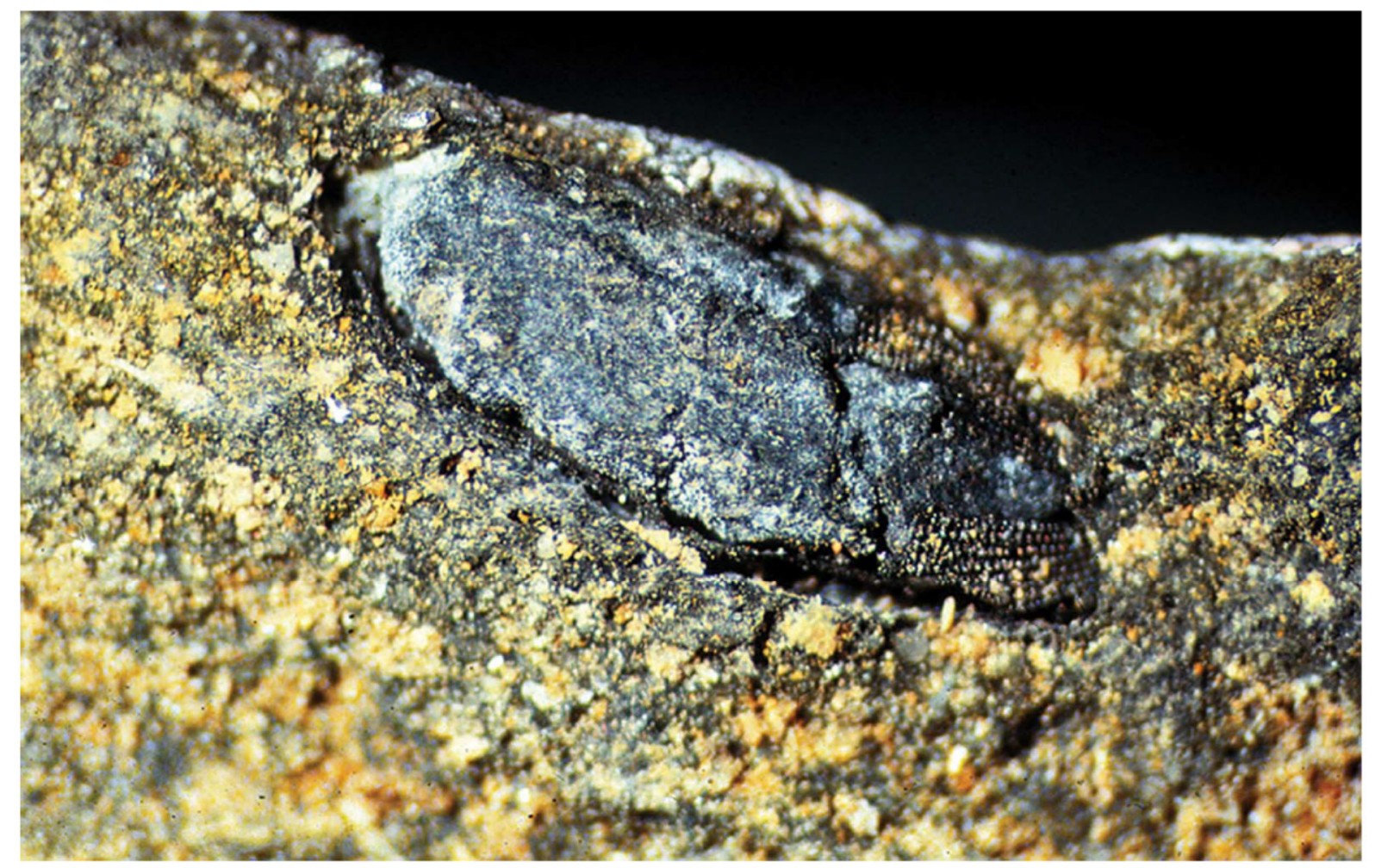

Figure 1. Photomicrograph of a fully charred Oryza grain embedded in the surface of the older sherd. The grain was AMS-dated to 4960-3565 cal BP (CAMS-725; Bellwood et al. 1992). Note the partial husk on the exterior with its distinctive 'checkerboard' pattern. No scale on original. Image courtesy of R. Gillespie. 

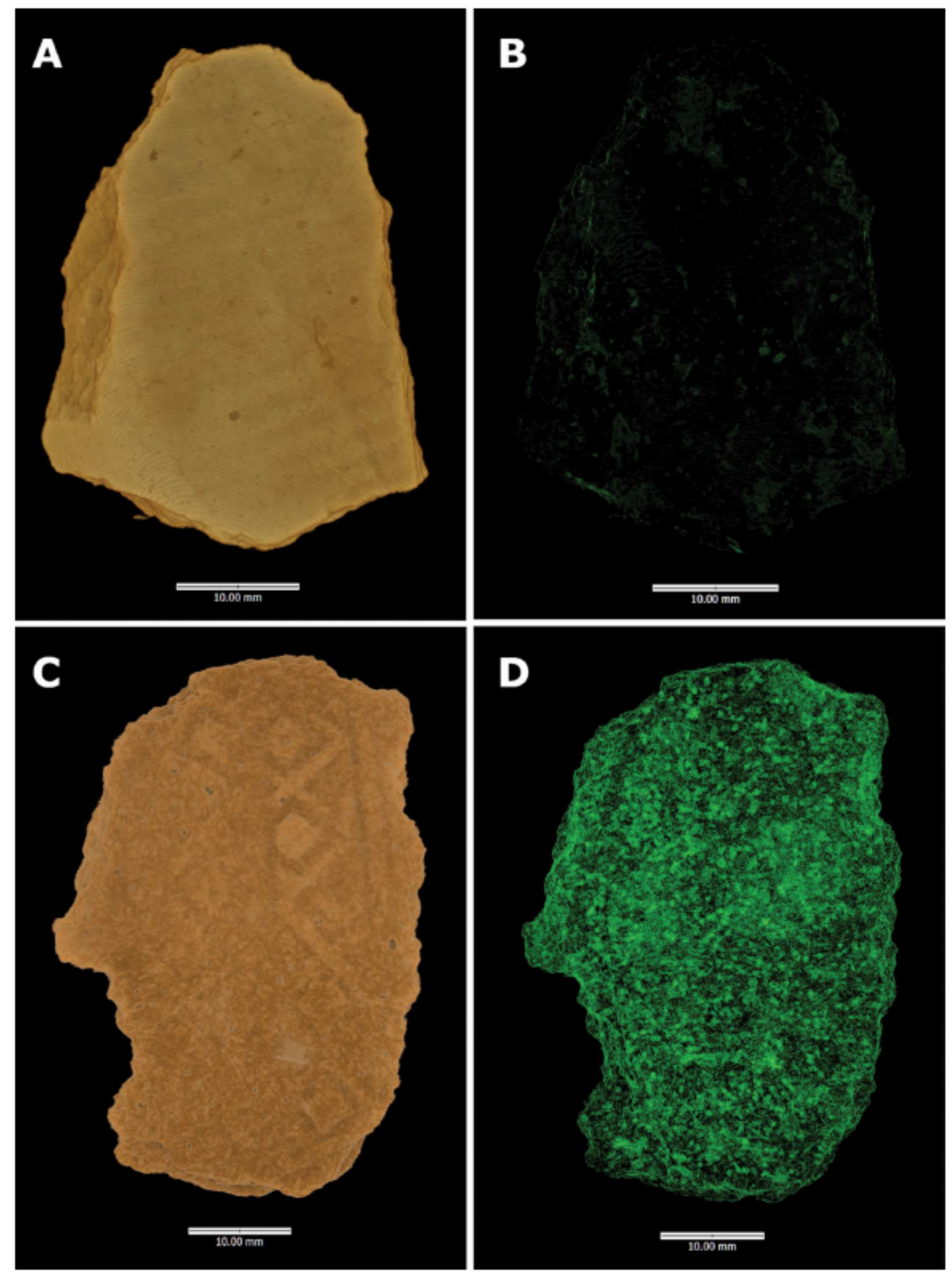

Figure 2. Virtual images showing clay (left) and organic (right) fractions within the older sherd, CAMS-725 (A-B) and the more recent sherd, CAMS-721 (C-D). The clay fraction is in brown, representing the external surface of a sherd. The organic fraction depicts in green all organic inclusions within a sherd. Images by Aleese Barron. 

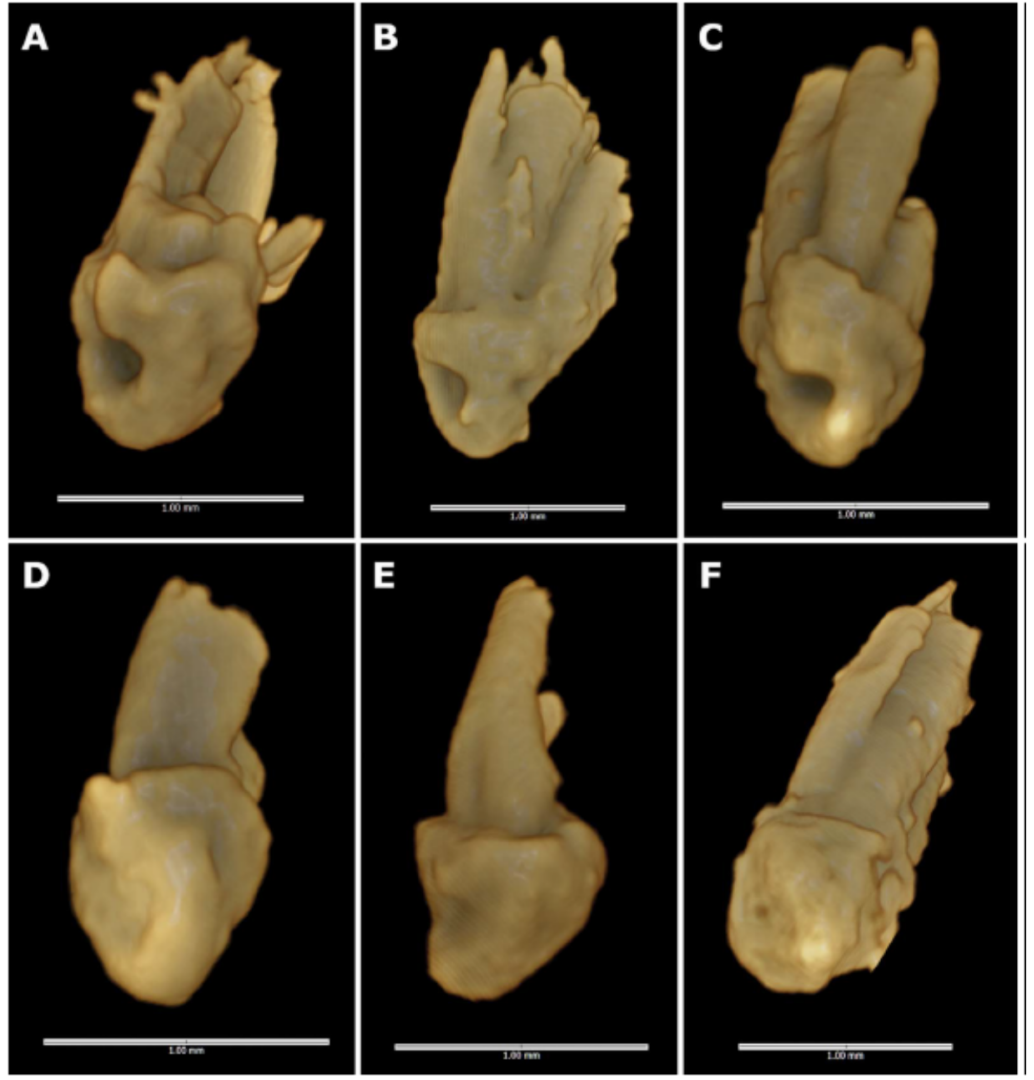

Figure 3. Visualisations of spikelet bases included within the more recent sherd (CAMS-721), illustrating the presence of domesticated types (A-C; inclusions 22, 23 and 32, respectively), an indeterminate type (D; inclusion 25) and wild types ( $E-F$; inclusions 35 and 27).

Visualisations of fifty spikelet base inclusions within this sherd are provided in the online supplementary material (OSM). Images by Aleese Barron. 


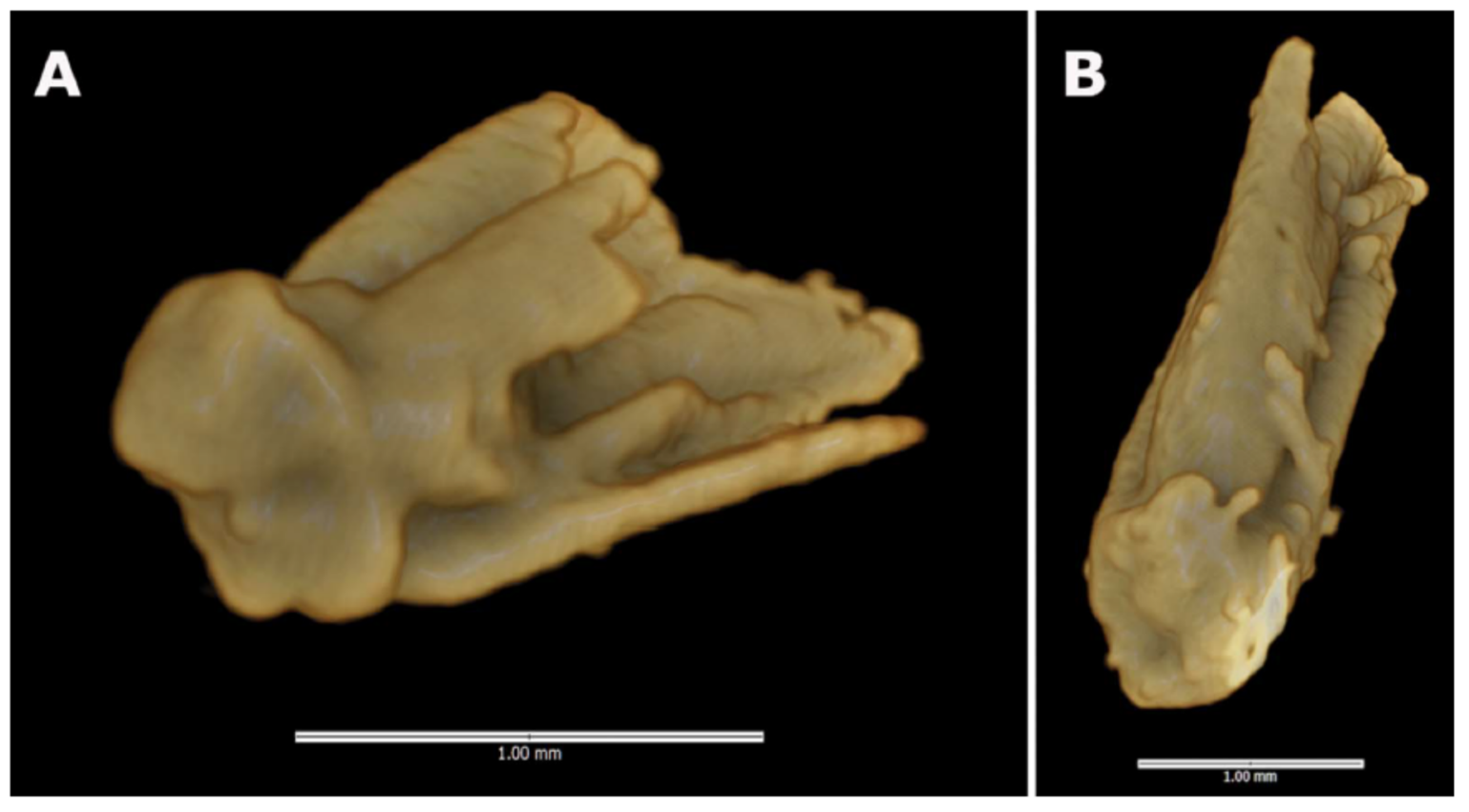

Figure 4. Visualisation of spikelet bases included within the more recent sherd (CAMS-721), showing two spikelet bases derived from a non-AA genome wild rice species that was probably indigenous to Borneo (A-B; inclusions 17 and 29, respectively). Images by Aleese Barron. 